\title{
FACTORS ASSOCIATED WITH ENDODONTIC FLARE-UPS
}

\author{
Shakeel-Ur-Rehman Khattak ${ }^{1}$, Ruqayya Sana ${ }^{1}$, Yasir Khattak ${ }^{1}$, Fiaz Alam ${ }^{1}$, Muhammad Zain Khan ${ }^{1}$ \\ 1. Sardar Begum Dental College
}

\begin{abstract}
OBJECTIVE:

The objective of the current study was to determine the frequency and factors of endodontic flare-ups and to compare the post obturation pain in single visit and multi visit root canal therapy, at the department of operative dentistry Sardar Begum Dental College (SBDC), Peshawar.
\end{abstract}

MATERIALS AND METHODS:

It was a cross sectional study, carried out at the department of operative dentistry, Sardar Begum Dental College, Peshawar. A total sample of 200 subjects was studied. Treatment protocols were standardized and, after taking informed consent endodontic procedure was carried out. Chi-square test was used to explore the relationship between endodontic flare ups with study variables.

\section{RESULTS:}

Our sample consisted of $54 \%$ females and $46 \%$ males. Frequency of endodontic flare ups was experienced by $48 \%$ subjects. $96.2 \%$ had used antibiotics, Endodontic flare ups was found to be significantly associated with gender, preoperative diagnosis , preoperative pain and medication while it was not found to be associated with any other variable studied.

\section{CONCLUSION:}

It was concluded that prevalence of post preparation pain during root canal treatment was high and significantly affected by pre -operative pain, preoperative diag nosis and medication. However, careful selection and adherence to the basic principles of endodontic therapy may reduce the occurrence of flare ups.

\section{KEY WORDS:}

Endodontic treatment, Flare-up, Root canal infection

\section{INTRODUCTION}

The aim of endodontic treatment is not only to conserve the tooth by removing the inflamed / infected contents of tooth but also to provide bacteria free environment for the healing

Correspondence:
Dr. Shakeel-Ur-Rehman Khattak
Sardar Begum Dental College
Contact:0333-3285967
Email: shak.khattak@gmail.com
https://doi.org/10.37762/jgmds.2-2.51
of peri -apical tissues. Aim is to provide stable and pain free masticatory unit. Severe pain and/or swelling following root canal treatment (RCT) are serious sequelae, upsetting to both, the patient and dentist. ${ }^{1}$ Flare-up is one c omplication of endodontic treatment, defined as acute exacerbation of asymptomatic pulp or periradicular pathosis after the initiation or continuation of root canal treatment. ${ }^{1}$ Other characteristics are occurrence of pain and/or swelling during endodontidreatment ${ }^{2}$ or pain and/or swelling that require non-intentional treatment, including active interference from the dentis\}. Lack of an exact definition of flare-up resulted in estimated frequency differences from as low as $1.5 \%{ }^{4}$ to as high as $20 \%{ }^{5}$. In addition, there is no unified opinion as to the reasons for flare -up progression. The present accepted hypotheses describe flare -up as a poly -etiologic phenomenon, whereas mechanical factors (preparation beyond apical terminus, over instrumentation, pushing dentin chips and the remainder of the infected pulp tissue into the peri -apical area, overextension of root canal filling), chemical factors (irrigants, intra-canal dressings, and sealers), and microbiologic factors contribute to its appearance ${ }^{6}$. 
Although many factors associated with flare -ups have been examined, those factors frequently related to the occurrence of flare -ups include the gender and age of patients 7 , the presence of a peri-apical lesion ${ }^{8,9,10}$, and a history of preoperative pain ${ }^{8,9}$. Infection is considered as the most significant factor in flare-up pathogenesis ${ }^{11}$. Pushing an infected organic substance into the peri -apical region during root canal preparation might cause exacerbation ${ }^{11}$ Another hypothesis is selective growth of certain ba cterial species inside the root canal as a result of ecologic changes during endodontic therapy ${ }^{11}$ Consequently, acute reaction of the peri -apical tissues might occur. In addition, new microorganisms might penetrate into the root canal from the oral cavity as a result of non -meticulous root canal preparation or inappropriate temporary sealing in multi -appointment therapy that could lead to flare $\quad$ ups $^{11}$ The intensity of the inflammatory reaction might be influenced by various factors such as extent of existerptathologic changes in the peri-apical region ${ }^{12}$, presence of specific bacterial species in the root canal ${ }^{13}$, tooth type, pulp diagnosis, occurrence of preoperative pain, and presence of a sinus tract ${ }^{35}$.

Endodontic therapy (initial root canal therapy as opposed to recurrent treatment, one or multi-appointment therapy, leaving the tooth "open" between appointments) plays an important role in evolving exacerbation of inflammation in the peri -radicular region. ${ }^{34}$ Although there is abundant information in the literature, it is a challenge to unequivocally conclude the pathogenesis and frequency of flare-ups and to indicate factors that affect them. The objective of this study was to determine the incidence and factors of endodontic flare ups at the departmen of operative dentistry Sardar Begum Dental College(SBDC), Peshawar and to compare the post obturation pain in single visit with multi visit root canal therapy.

\section{MATERIALS AND METHODS}

This Cross sectional analytical study was conducted at the department of operative dentistry, Sardar Begum Dental College (SBDC), Peshawar. Duration of study was 6 months from $23^{\text {rd }}$ march 2015 to 23 rd September 2015. Approval was taken from research ethical committee of SBDC, Peshawar. After taking medical history, conducting a dental examination and obtaining pre-operative radiographs, patients meeting the inclusion criteria were selected. Permanent teeth requiring root canal treatment for pulpal, peri-apical or elective reasons were included in the study. Previously root tre ated teeth, teeth with peri-apical abscess, mobile teeth (grade II and above), teeth with vertical fracture and third molars were excluded from the study. Written informed consent was obtained from all the participantsBoth males and females ranging in age from 14 years to 80 years were included in the study. Each patient's demographics, the tooth position, presenting symptoms, and the presence or absence of preoperative pain (spontaneous or percussion pain) were obtained at the patient's first visit. The pulpal (normal, irreversible pulpitis, pulp necrosis, reversible pulpitis, or previously treated) and peri -apical diagnosis (normal, chronic apical periodontitis, acute apical periodontitis, chronic peri -apical abscess, acute peri -apical abscess, or a non -endodontic lesion) of each treated tooth were recorded. Treatment protocols were standardized: each patient was anesthetized with $2 \%$ Lidocaine with or without epinephrine, a rubber dam was put in place, and a $0.5 \% \mathrm{NaOCl}$ solution was used for irrigation of the root canal throughout the treatment. The working length (from the crown to $0.5 \mathrm{~mm}$ above the anatomical root apex) was measured using an electronic apex locator and confirmed by peri -apical radiography. Apical preparation was completed to the working length with either hand -held stainless steel files or nickel -titanium rotary instruments. All RCT cases were obturated either on the same vi sit or on next appointment with gutta-percha cones using a lateral condensation. Root canal overfilling was defined asfinding gutta-percha or sealer beyond the radiographic apex. Operators decided the best time to obturate the root canals based on the diagnosis of each tooth, clinical findings, and available chair time. Calcium hydroxide was the only intra -canal medication put in place if completing the RCT required more than 1 visit. Patients were instructed to call the 
dentist or come back for an emergency visit if the tooth was severely painful or swelling developed at the gingival or alveolar mucosa during the first $24 \mathrm{hrs}$ or 2-3 days after treatment. If a patient called with a complaint of severe pain and/or swelling and returned to the clinic for emergency treatment, a flare-up was recorded. Every patient was given aPerforma to mark their pain on Visual analogue pa in scale during first 24 hours and after 24 hours till 3 days Flare-up was recorded on Visual analogue scale (VAS). VAS was divided into no pain, mild pain, moderate pain and severe pain. Patients who reported with moderate to severe pain were considered a s flare -up. The overall incidence of endodontic flare -ups was calculated. The associations between the occurrence of flare -ups and various related factors such as patients' demographics, the tooth position, pret reatment symptoms, the pulpal, peri-radicular diagnosis and number of appointments were analyzed by the Chi -squared test. A p v alue of $\leq 0.05$ was considered statistically significant.

\section{RESULTS}

A total of 200 patients were included in the study. Results showed that mean age of the subjects was $35.45+--14.3$ with an age range from 14 years to 80 years. Table $154 \%$ of the subjects were female and $46 \%$ were males. In this study $72 \%$ were multiple rooted teeth and $28 \%$ were single rooted teeth. $66 \%$ teeth were treated in multiple visits while in single visit $34 \%$ teeth were treated. (Table 2)

Distribution of subjects with respect to preoperafive diagnosis was shown in Figure1 with $66.33 \%$ of acute apical pathosis , $40.20 \%$ of chronic apical pathosis , $38.19 \%$ of irreversible pulpitis, $34.17 \%$ of pulpal necrosis and other pulpo-peri-apical conditions were $22.11 \%$.

Results showed that moderate pain wa s found to be $48 \%$ followed by $46 \%$ mild pain , $40 \%$ no pain and $20 \%$ experienced severe pain. Figure 2

Regarding self medication which patient had after initial visit $92.46 \%$ had antibiotics $60.30 \%$ had analgesics, $40.20 \%$ had both antibiotics along with analge sics and $8.4 \%$ had not taken any drugs. Figure 3

Table 3 highlights the factors that were associated with endodontic flare ups in the present study. Gender, tooth type, preoperative diagnosis, preoperative pain and medication were found significantly assoc iated with endodontic flare ups with $p$ value $<0.05$, while tooth type and number of appointments were not significantly related to endodontic flare ups.

Tables 1: Age Distribution

\begin{tabular}{|c|c|c|c|c|c|}
\hline & $\mathbf{N}$ & Minimum & Maximum & Mean & Std. Deviation \\
\hline Age & 200 & 14 & 80 & 35.45 & 14.311 \\
\hline
\end{tabular}

Table 2: Frequency of deferent variable in the study

\begin{tabular}{|l|c|c|}
\hline \multicolumn{2}{|c|}{ Variables } & Percentage \\
\hline \multirow{2}{*}{ Gender } & Male & $54 \%$ \\
\cline { 2 - 3 } & Female & $46 \%$ \\
\hline \multirow{2}{*}{ Nype of tooth visit } & Single Rooted & $72 \%$ \\
\cline { 2 - 3 } & Multiple Rooted & $28 \%$ \\
\cline { 2 - 3 } & Single visit & $66 \%$ \\
\hline
\end{tabular}


Figure \# 1: shows distribution of subjects with respect to preoperative diagnosis.

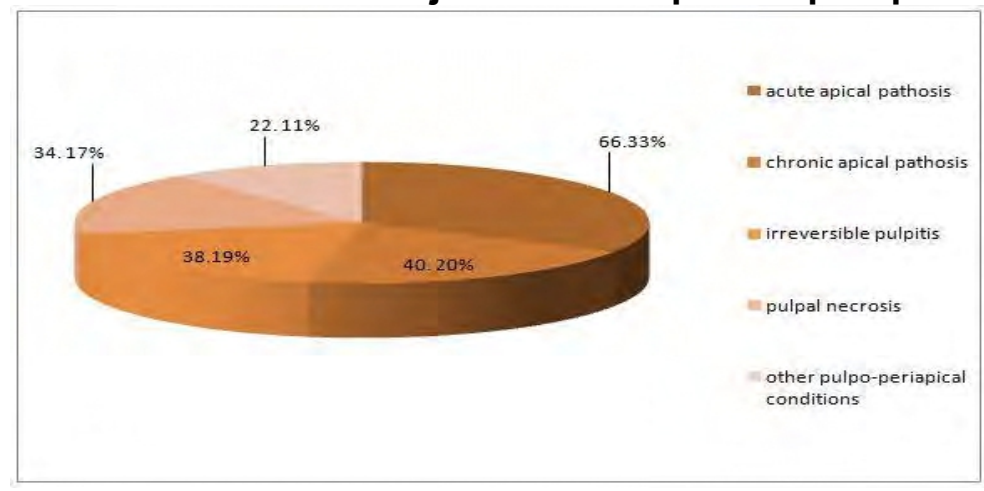

Figure \# 2: Preoperative pain status

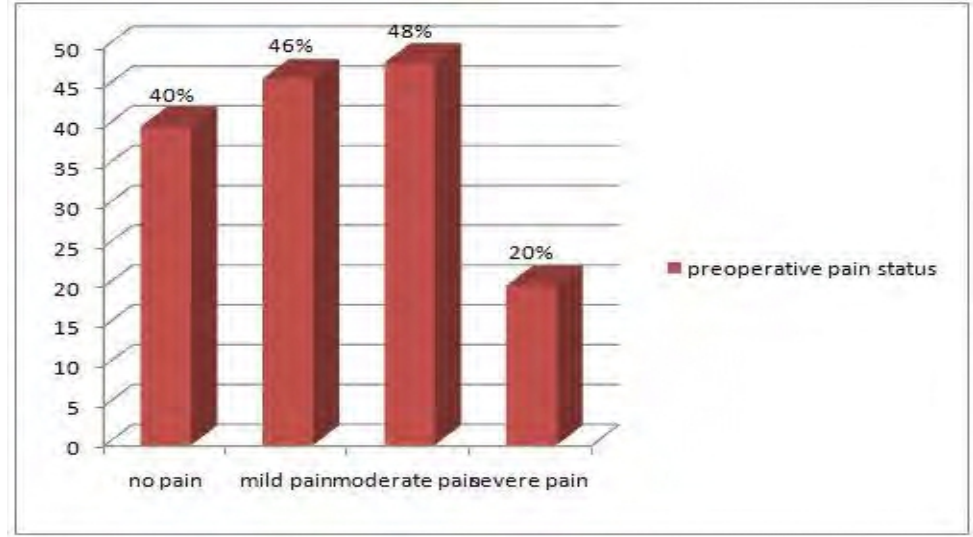

Figure \# 3: Types of Self medication

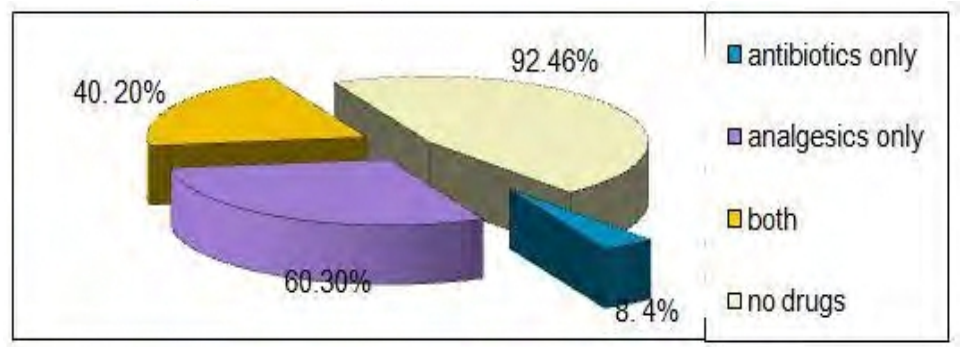

Table 3: Variables associated with flare-ups. 


\begin{tabular}{|l|l|l|}
\hline Variables & Category & p value \\
\hline Gender & $\begin{array}{l}\text { Male } \\
\text { female }\end{array}$ & $\mathbf{0 . 0 1 1}$ \\
\hline Tooth type & $\begin{array}{l}\text { Single rooted } \\
\text { Multi rooted }\end{array}$ & 0.743 \\
\hline Appointment & $\begin{array}{l}\text { Single visit } \\
\text { Multi visit }\end{array}$ & 0.431 \\
\hline $\begin{array}{l}\text { Pre-operative } \\
\text { Diagnosis }\end{array}$ & $\begin{array}{l}\text { Necrotic } \\
\text { Elective } \\
\text { Irreversible } \\
\text { Chronic Apical pathosis } \\
\text { Acute Apical pathosis }\end{array}$ & $\mathbf{0 . 0 0 1}$ \\
\hline Preoperative pain & $\begin{array}{l}\text { No pain } \\
\text { Mild pain } \\
\text { Moderate pain } \\
\text { Severe pain }\end{array}$ & $\mathbf{0 . 0 0 1}$ \\
\hline Medication & $\begin{array}{l}\text { No medication } \\
\text { Analgesic } \\
\text { Antibiotics } \\
\text { Both drugs }\end{array}$ & $\mathbf{0 . 0 0 1}$ \\
\hline
\end{tabular}

\section{DISCUSSION}

Pain perception is a highly subjective and variable experience modulated by multiple physical and psychological factors, and pain reporting is influenced by factors other than the experimental procedure.$^{14}$ Different scales and methods have been used to assess pain after endodontic therapy ${ }^{15}$ In the current study visual analog scale (VAS) was used as a result of its valid and reliable ratio scale to measure pain. The high prevalence of pain $\mathrm{n}$ our experience was consistent with a similar study by O' Keefe and Meta et al. ${ }^{16}$

This pain prevalence was higher than reported by $\mathrm{Clem}^{17}$ and Maddox et $\mathrm{al}^{18}$, which could be due to various populations receiving treatment, different treatment techniques, an $d$ various numbers and experience of operators. Our results were in agreement with O'Keefe ${ }^{16}$, Torabinejad et al(19), Mor $\mathrm{C}$ et al ${ }^{20}$ and Siqueira et al. ${ }^{21}$ that presence of pre - operative pain is significantly associated with post - operative pain. There are con flicting results with regards to influence of tooth type on the prevalence of postoperative pain. Several studies associate molar teeth with greater susceptibility to pain ${ }^{22}$. Although results of our study show that there is no significant difference in flare up in single or multiple visits Root Canal Treatment, number of flare up in single visit were less as compared to multiple visits. Reason for this less flare up in single visit may be due to(denying any space for irriatants or bacterias ' by immediately obturationg canal) bacteria or other irritants are not allowed to remain in the empty canal. ${ }^{23,}{ }^{24}$ Another possible reason for fewer one visit flare ups is the deletion of the intra -canal medication, which may elicit an immune reaction. ${ }^{25,} 26$ Still, another possibility is that early sealing of the canal eliminates bacterial ingress from a leaky restoration, lateral canal, or caries. During single visit endodontic treatment, the clinician is well versed with the internal anatomy of that treating tooth, and good tactile sense while instrumenting the canals, this may probably also help in fewer flare ups. Isolation of areas of inadequate instrumentation and/or other irritants within the canals is yet another plausible reason for higher multiple visit flare ups. Use of preoperative antibiotic reduces the chances of flare up during endodontic treatment which is same as the work of Walton and Chiappinelli ${ }^{27}$. In necrotic teeth and teeth with symptomatic irreversible pulpitis canal is flooded with micro-organisms which are the major cause of endodontic flare-up.

Antibiotics act against these microorganisms either by inhibiting their growth or by killing them and reducing bacterial count in peri -apical tissues. Current study shows no significant difference between male and female although previous studies show that chances of flare up 
are more in females. Fluctuating female hormone levels cause an increased level of serotonin and nor adrenaline leading to increased pain prevalence during the menstrual period and in women receiving hormonal replacement therapy or oral contraceptives ${ }^{28}$ In this study age had no significant relationship with rate of endodontic flare up. These results are similar to the work of Oginni and Udoye ${ }^{29}$ who found no relation between rate of flare-ups and age. Similar findings were also reported by Morse et al and Eleazer and Eleazer. ${ }^{30}$ However, Balaban et al treated necrotic teeth and found that there was a greater tendency to develop flare up in patients less than 50 years old. The decrease in patients' response might be related to decreased pulp canal size, decrease blood flow to alveolus and decreased inflammatory responses in older patients. Since this is a hospital based study it does not represent general population.

\section{CONCLUSION}

Within the limitations of this study we can conclude that prevalence of post preparation pain during root canal treatment was high and significantly affected by pre -operative pain, preoperative diagnosis and medication. However, careful selection and adherence to the ba sic principles of endodontic therapy may reduce the incidence of flare ups.

\section{REFERENCES}

1. American Association of Endodontists. Glossary of endodontic terms, 7th ed. Chicago: American Association of Endodontists; 2003.

2. Harrington GW, Natkin E. Mid-treatment flare-ups. Dent Clin North Am 1992;36:409 -23.

3. Walton RE, Fouad A. Endodontic interappointment flare-ups: a prospective study of incidence and related factors. J Endod 1992;18:172-7.

4. Imura N, Zuolo ML. Factors associated with endodontic flare -ups: a prospective study. IntEndod J 1995;28:261-5.

5. Morse DR, Koren LZ, Esposito JV, Goldberg JM, Sinai IH, Furst ML. Asymptomatic teeth with necrotic pulps and associated periapicalradiolucencies: relationship of flare -ups to endodontic instrumentation, antibiotic usage and stress in three separated practices at three different time periods: part 1:-1963-1970. Int J Psychosom 1986;33:5-17.

6. Seltzer S, Naidorf IJ. Flare -ups in endodontics: part I —etiological factors. J Endod1985;11:472 8.

7. Torabinejad M, Kettering JD, Mcgraw JC, Cummings RR, Dwyer TG, Tobias TT. Factors associated with endodontic interappointment emergencies of teeth with necrotic pulps. $J$ Endod, 14: 261-266, 1988.

8. Richard W, Ashraf F. Endodontic interappointment flare-ups: a prospective study of incidence and related factors. J Endod, 18: 172-177, 1992

9. Richard W, Ashraf F. Endodontic interappointment flare-ups: a prospective study of incidence and related factors. J Endod, 18: 172-177, 1992

10. Goldman M, Rankin C, Mehlman R, Santa C. The immunologi c implications and clinical management of the endodontic flare-up.CompendContinEduc Dent, 10: 126-130, 1987

11. Siqueira JF Jr. Microbial causes of endodontic flare-ups. IntEndod J 2003;36:453-63

12. Trowbridge HO, Emling RC. Inflammation: a review of the process. 5th ed. Chicago: Quintessence, 1997. 
13. Chavez de Paz Villanueva LE. Fusobacteriumnucleatumin endodontic flare -ups. Oral Surg Oral Med Oral Pathol Oral RadiolEndod 2002;93:179-8

14. Bender IB. Pulpal pain diagnosis: a review. J Endod 2000;26:175-9.

15. Al-Negrish AR, Habahbeh $R$. Flare up rate related to root canal treatment of asymptomatic pulpally necrotic central incisor teeth in patients attending a military hospital. J Dent 2006;34:635 - 40. Epub 2006 Jan 24.

16. O Keefe. The opiate receptors. Pain: current concepts on pain andanalgesia. Vol. 4. New York: Burroughs Wellcome Co., 1976:1.

17. Clem. Concepts of accidental overfilling and overinstrumentation in the mandibular canal during root canal treatment. J Endodon 1983;9:81.

18. Maddox,Balaban FS, Skidmore AE, Gr iffin JA. Acute exacerbations following initial treatment of necrotic pulps. J Endodon 1984;10:78.

19. Torabinejad M, Kettering JD, McGraw JC, Cummings RR, Dwyer TG, Tobias TS. Factorsassociated with endodontic inter -appointment emergencies of teeth with necr oticpulps. $J$ Endod 1988;14:261- 6.

20. .Mor C, Rotstein I, Friedman S. Incidence of interappointment emergency associatedwith endodontic therapy. J Endod 1992;18:509 -11.

21. Siqueira JF Jr. Microbial causes of endodontic flare-ups. IntEndod J2003;36:453-63.

22. Ehrmann EH. Endodontic cellulitis 'flare-up': clinical implications. Aust Dent J1996;41:62-3.

23. Fava $L R G, A$ comparision of one versus two appointment endodontic therapy in teeth with non vitalpulps, IEJ 1989,22,179-183

24. .Mulhern JM,Patterson SS etal,Incidence of postoperative pain after one-appointment endodontic treatment of asymptomatic pulpal necrosis in single rooted teeth.JOE 1992,8,370-375.

25. .NaidorflJ,Endodontic flare ups;bacteriological and immunological mechanisms.JOE $1985,11,462-464$

26. Roane JB,DrydenJA, etal,Incidence of postoperative pain after single and multi -visit endodontic procedures, OralSurg 1983,55,68-72

27. Walton RE, Chiappinelli J. Prophylactic penicillin: effect on post treatment symptoms following root canal treatment of asymptomatic periapicalpathosis. J Endod. 1993;19(9):466-70.

28. Y.-L. Ng, J.P.Glennon, D.J. Setchell, K.Gulabivala, prevalence of and factors affecting post obturation pain in patients undergoing root canal treatment, International endodontic journal, (37) , 2004, 1-391

29. Oginni AO, Udoye Cl.Endodntic flare up: comparison of incidence between single and multi visit procedures in patients. BMC Oral health 2004;4:4.

30. Morse KD, Koren LZ, Esposite JV. Infection flare up and their prevention.Int J Psychosm 1986;33:2-3.

(c) (1) (2)(2)

LICENSE: JGMDS publishes its articles under a Creative Commons Attribution Non-Commercial Share-Alike license (CC-BY-NC-SA 4.0). COPYRIGHTS: Authors retain the rights without any restrictions to freely download, print, share and disseminate the article for any lawful purpose. It includes scholarly networks such as Research Gate, Google Scholar, LinkedIn, Academia.edu, Twitter, and other academic or professional networking sites. 